\title{
Arquitetura sob a ótica da humanização em ambientes de quimioterapia pediátrica
}

\author{
Architecture from the perspective of the humanisation of \\ pediatric chemotherapy environments
}

\section{Andrea D'Angelo Leitner Silvia Mikami Pina}

\section{Resumo}

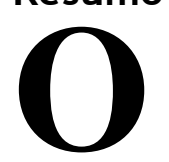

artigo apresenta os resultados de uma pesquisa quali-quantitativa sobre projeto no âmbito da humanização da arquitetura hospitalar em ambientes de quimioterapia pediátrica. $\mathrm{O}$ contexto aponta uma dinâmica acelerada de adaptação dos ambientes de saúdediante da introdução constante de tecnologias médicas avançadas. O objetivo é identificar e validar estratégias projetuais potentes em centros pediátricos de infusão, visando subsidiar rearranjos das configurações existentes e fundamentar novos projetos no âmbito da humanização no contexto especificado. A metodologia de Avaliação Pós-Ocupação foi aplicada em estudo de caso referencial, amparada por entrevistas com grupo de especialistas brasileiros e pela análise de quatro benchmarks da literatura internacional. Os resultados indicam as implicações ambientais decorrentes da prevalência do tratamento quimioterápico ambulatorial sobre o regime de internação e a importância da contribuição dos voluntários. Também sobressaem os recursos recentes de humanização da arquitetura, como o desenvolvimento de ambientes que curam, centrados na família, flexíveis, com wayfinding evidente e distrações positivas e inovadoras, como os ambientes de reabilitação social. Os resultados alcançados estimulam novas pesquisas que identifiquem possíveis alternativas de atendimento aos usuários, fornecendo subsídios ao arquiteto para o aprimoramento do ambiente da saúde,mediante a adoção de uma visão estratégica sobre o futuro.

Palavras-chave: Humanização da arquitetura. Ambientes de quimioterapia pediátrica. Processo de projeto. Avaliação Pós-Ocupação. Hospitais contemporâneos.

\begin{abstract}
This article presents the results of a qualitative and quantitative research on architecture design in the scope of the humanisation of hospital architecture in pediatric chemotherapy environments. The context points towards the accelerated adaptation of health environments in face of the introduction of advanced medical technologies. The goal is to identify the main factors that affect quality in the design process of this type of environment, in order to offer better care for child patients and other users. The Post-Occupancy Evaluation methodology was applied in a reference case study supported by interviews with a group of Brazilian experts and an analysis of four benchmarks in the international literature. The results indicate the environmental implications arising from the prevalence of outpatient chemotherapy treatment over the hospitalisation regime, and the importance of volunteer contributions. They also point to recent

humanising features, such as the development of healing, family-centred, flexible environments, with evident wayfindingfeatures and innovative and positive distractions, such as social rehabilitation environments. The achieved results stimulate new research that identifies better alternatives to meet users' needs and provide support to architects to improve health environments by adopting a strategic vision of their future.
\end{abstract}

${ }^{1}$ Andrea D'Angelo Leitner 'Universidade Estadual de Campinas Campinas - SP - Brasil

${ }^{2}$ Silvia Mikami Pina ${ }^{2}$ Universidade Estadual de Campinas Campinas - SP - Brasil

Recebido em 05/12/19 Aceito em 23/03/20
Keywords: Architecture humanisation. Pediatric chemotherapy environment. Design process. Post Occupancy Evaluation. Contemporary hospitals. 


\section{Introdução}

No contexto do processo de projeto de arquitetura, a valorização do indivíduo e de suas necessidades tem sido incorporada por uma diversidade de metodologias participativas que buscam envolver e conscientizar o usuário de seu papel em um projeto arquitetônico de sucesso. Em projetos para estabelecimentos de saúde, esse envolvimento dos usuários é reconhecido e valorizado, sobretudo em situações exacerbadas pela complexidade ou gravidade do tratamento, como ambientes de quimioterapia pediátrica. Tais circunstâncias requerem estratégias que estimulem a reunião dos aspectos notáveis de uma arquitetura mais humanizadora.

No atendimento assistencial à criança, a RDC 50 (ASSOCIAÇÃO..., 2002) recomenda a diferenciação dos espaços do adulto e da criança em setores como unidades de quimioterapia. Nos últimos dez anos, relatos no campo da enfermagem são alicerçados no modelo que coloca a criança paciente no foco de atenção, e a instituição se adapta a ela (PEDRO et al., 2016). O ambulatório infantil se configura como um importante marco na assistência e o ambiente exclusivamente voltado para as crianças contribui positivamente para o acolhimento.

O objetivo do trabalho é identificar e validar estratégias potentes de projeto de centros de infusão pediátricos visando subsidiar eventuais rearranjos das configurações existentes e fundamentar novos projetos similares no âmbito da humanização, de forma a colaborar com o melhor atendimento às expectativas dos usuários.

Parte-se da hipótese de que distrações positivas como ambientes recreativos e interativos permitem a realização de atividades individuais e em grupo, reforçam o acolhimento, a aceitação ao tratamento e o retorno às várias sessões da atividade. Esse conjunto contribui plenamente para a recuperação e melhor quadro de saúde dos pacientes.

A pesquisa é motivada pelo papel da arquitetura de ambientes de quimioterapia pediátrica de responder com qualidade às necessidades dos usuários diante das inovações médicas e tecnológicas que se impõem ${ }^{1}$.

Para a pesquisa foi realizada a Avaliação Pós-Ocupação (APO) de um estudo de caso referencial, o Centro Infantil Boldrini (CIB), situado em Campinas, SP, amparada pelo estudo da literatura e de quatro benchmarks nela constantes, por entrevistas com seis especialistas brasileiros sobre o tema e dois voluntários, e pelo estudo dos principais requisitos normativos da área.

\section{Aspectos teóricos e práticos da humanização da arquitetura da saúde}

A preocupação dos conceitos humanizadores vinculados ao ambiente hospitalar se deu apenas a partir de meados do século XX, quando, por influência da sociologia e da antropologia interessadas na ampliação do foco de discussão sobre saúde e doença, se iniciou o debate sobre a necessária renovação dos espaços hospitalares (LUKIANTOCHUKI; SOUZA, 2010). Mesmo assim, são diversas as abordagens e conceitos vigentes para a incorporação da humanização. Contudo, o consenso dessa atenção se dá para os hospitais pediátricos, pois nestes a busca pela humanização é mais premente.

A revisão sistemática realizada sobre a humanização da arquitetura hospitalar em ambientes de quimioterapia pediátrica, entre 2008 e 2018, teve a maior concentração de publicações selecionadas nos campos da arquitetura e da enfermagem. A produção europeia e a americana enfatizam a cura global da criança e o apoio a sua família em todas as fases da terapia. A produção latino-americana enfoca a importância da ambientação lúdica, com menor ênfase ao bem-estar familiar. A desospitalização é a principal indicação, estimulando a produção de ambientes ambulatoriais que remetam às noções de identidade e território da criança paciente no projeto arquitetônico. As pesquisas de modo geral enfatizam a importância do ambiente lúdico no tratamento infantil e uma lacuna de conhecimento do ambiente dedicado ao acompanhante, ao paciente juvenil e ao voluntariado.

A Política Nacional de Humanização do Ministério da Saúde (PNH) (BRASIL, 2004) tem como pressuposto valorizar os diferentes atores do sistema - usuários, trabalhadores e acompanhantes - e suas dimensões subjetivas, culturais e clínicas. Uma prática humanizada é o conjunto de iniciativas que possibilita a prestação de cuidados capazes de conciliar a melhor tecnologia disponível com a promoção de acolhimento

${ }^{1}$ Este trabalho faz parte de uma pesquisa de pós-doutoramento no Programa de Pós-Graduação em Arquitetura, Tecnologia e Cidade da Unicamp.

180 Leitner, A. D.; Pina, S. M. 
dos usuários, respeito ético e cultural ao indivíduo assistido, bem como a geração de espaços de trabalhos adequados e a satisfação dos usuários.

Segundo Pessatti (2008), uma de suas diretrizes trata da ambiência na saúde que é o tratamento dado ao espaço físico para proporcionar atenção acolhedora, resolutiva e humana (BRASIL, 2006). A diretriz foca no respeito aos valores culturais e ao modo de vida de cada comunidade, desfazendo o mito de que espaços que abrigam serviços de saúde são necessariamente impessoais e hostis (Figura 1).

Do ponto de vista prático, os arquitetos Kuma, Houben e Rijke (MORENO, 2018) elegem cincomaneiras de humanizar edifícios da saúde pediátricos:

(a) transformando o tratamento em brincadeira;

(b) criando calor acolhedor;

(c) incluindo distrações positivas;

(d) simplificando a circulação; e

(e) adotando uma abordagem semelhante à cidade.

O tratamento amparado por brincadeira é uma forma de recuperação e se faz pela concepção de ambientes que ativam, motivam e capacitam a mente e o corpo do paciente. A atmosfera informal permite aos pacientes e suas famílias manterem suas rotinas diárias. Minimizar rotas e transferências de pacientes reduz o estresse e permite aos pacientes sentirem-se seguros e sob controle (Figura 2).

\section{Recentes e novas tecnologias}

Para Thomazoni (2016), os benefícios das recentes tecnologias têm impactos significativos sobre o edifício da saúde. O correio pneumático altera e alivia os percursos de materiais, enquanto o uso inteligente dos sistemas de transporte vertical de elevadores reduz o tempo de espera e o número de paradas; já as esteiras virtuais ampliam a capacidade de wayfinding, metodologia para promover material ou estudos de orientação espacial em comunicação visual.

Figura 1 - Ambiente de tratamento com respeito aos valores culturais da região Norte brasileira

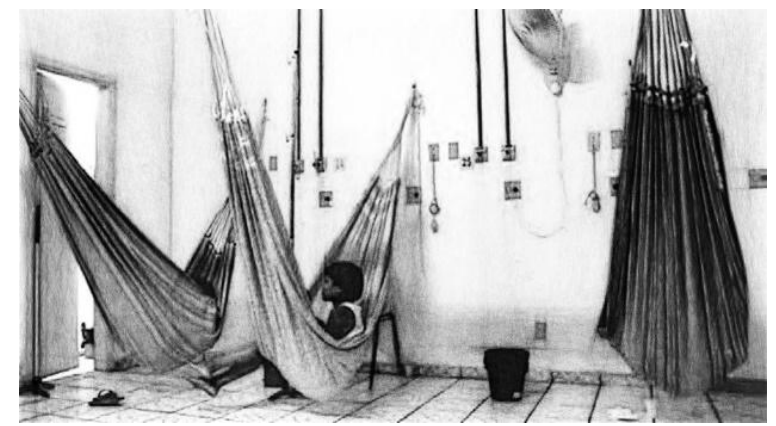

Fonte: releitura dos autores a partir do acervo do entrevistado arquiteto $\mathrm{B}$.

Figura 2 - Exemplos de humanização na arquitetura

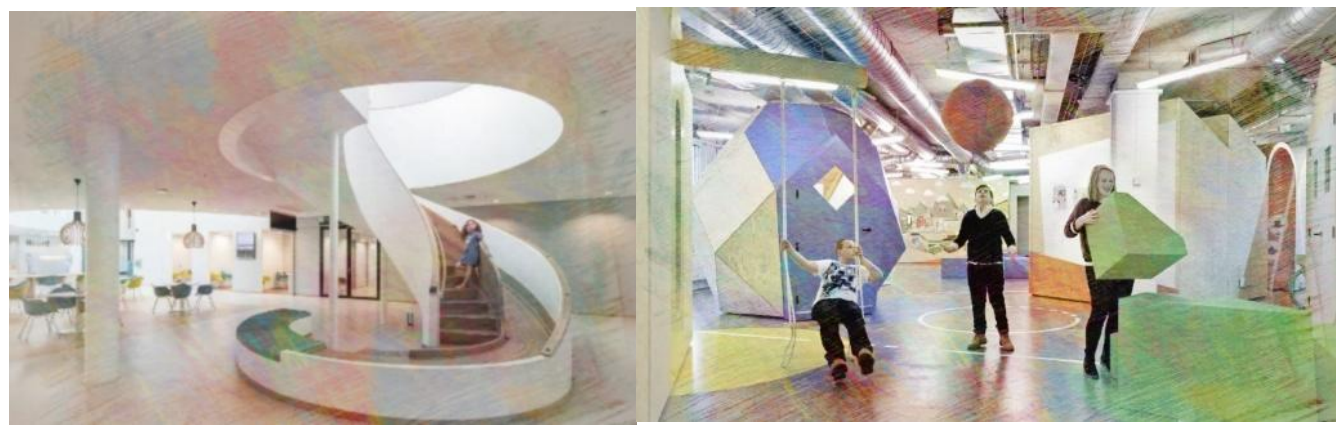

Fonte: releitura dos autores a partir de Moreno (2018). 
A Tecnologia da Informação e Comunicação em Saúde (TICS) permite o mapeamento digital de todos os processos realizados no edifício, com repercussão sobre seu planejamento estratégico. Uma ferramenta da TICS, o Prontuário Eletrônico do Paciente (PEP) permite que as informações sejam compartilhadas automaticamente com outros profissionais e instituições, possibilitando ser acessado pela equipe assistencial instantaneamente.

A telemedicina é um conjunto de tecnologias médicas remotas avançadas que permite a realização de ações médicas a distância; usada por instituições que buscam outras de referência para trocar informações, a telemedicina congrega a redução de custos com a atuação médica no acompanhamento remoto dos resultados de exames, na execução de discussões técnicas, no auxílio ao diagnóstico, na assistência aos pacientes crônicos, e outros, e reduz a frequência dos pacientes ao hospital, diminuindo a pressão sobre estes, já comprometidos pela falta de leitos e de recursos.

Recentemente, dispositivos móveis têm permitido o monitoramento da saúde do paciente à distância, dando suporte à desospitalização. A utilização da tecnologia para monitorar e promover cuidados e maior adesão aos tratamentos produz melhor integração entre a equipe multiprofissional e o paciente.

\section{Benchmarks, estudos de caso}

A análise de hospitais da literatura atual se concentrou na seleção de benchmarks, hospitais recentes, com menos de 10 anos de projeto ou de operação, e referências no quesito de humanização da arquitetura. Foram analisados o Suzhou Children's Hospital, o Ann \& Robert H. Lurie Children's Hospital, o Hospital Infantil Nemours e o Centro de Câncer da Universidade do Arizona. Esses hospitais depositam seu foco no cuidado da saúde, e não da doença, o que fundamenta a concepção de edifícios mais atraentes e ambientes mais interativos com os usuários, aproximando-se efetivamente das demandas contemporâneas no cuidado da saúde.

Além deles, o Centro Infantil Boldrini (CIB), estudo de caso central da pesquisa, foi avaliado por meio da APO. O estudo de caso brasileiro foi considerado benchmark pelas características identificadas com os princípios da PNH,adotada pelo Governo Federal.

O Hospital Infantil de Suzhou, localizado na China, foi projetado pelo escritório HKS Architecture em 2010. O programa totalizou $94.800 \mathrm{~m}^{2}$ e 800 leitos. O edifício foi inspirado na forma da pipa que se eleva sobre o jardim e áreas de lazer, fazendo uso de cores diversas, o que distrai as crianças pacientes e os demais usuários (Figura 3).

O Ann \& Robert H. LurieChildren's Hospital, localizado em Chicago, EUA, foi projetado pelos escritórios ZGF Architects, SolomonCordwellBuenz e Anderson Mikos Architects, e inaugurado em 2012. O edifício está localizado em área urbana, é um monobloco vertical de 23 pavimentos, que totaliza $116.128,80 \mathrm{~m}^{2} \mathrm{e}$ 360 leitos. O edifício tem boa setorização e presença de pavimentos técnicos intermediários, sem área para expansões (Figura 4).

O Hospital Infantil Nemours, com área construída de $192.000 \mathrm{~m}^{2}$ e 95 leitos, está situado em Orlando,EUA, e foi projetado por Stanley Beaman \& Sears em 2012. O hospital corrobora o termo "ambiente de cura", cujo sentido é auxiliar efetivamente na cura de pacientes, tranquilizando os pais e encantando as crianças. A solução arquitetônica resulta da colaboração de profissionais, administradores e um comitê familiar de pais e crianças, que consolida o trabalho multidisciplinar e interdisciplinar das equipes (Figura 5).

Figura 3 - Suzhou Children's Hospital

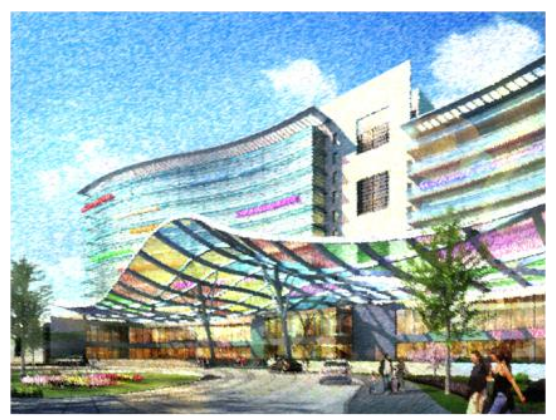

Fonte: releitura dos autores a partir de Jordana (2011).

182 Leitner, A. D.; Pina, S. M. 
Figura 4 - Ann \& Robert H. Lurie Children's Hospital

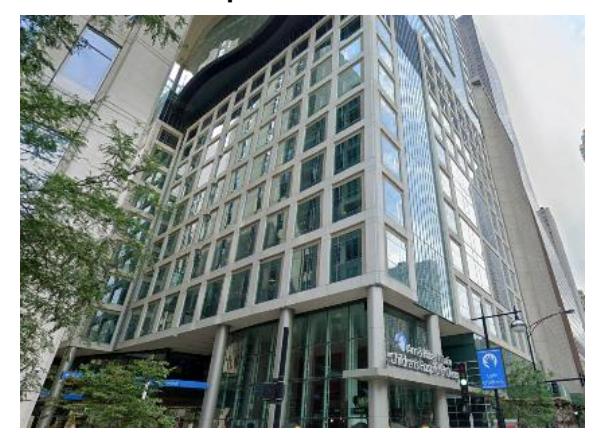

Figura 5 - Hospital Infantil Nemours

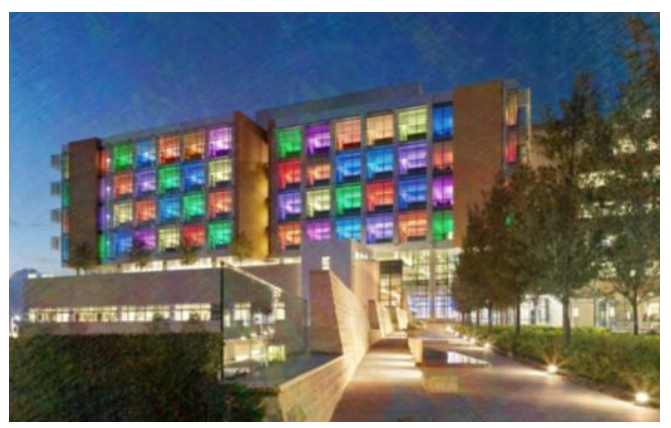

O Centro de Câncer da Universidade do Arizona é um edifício dedicado ao tratamento de câncer, mas não é exclusivamente pediátrico. Localiza-se no campus da universidade de Phoenix, possui área construída de 20.438,67 $\mathrm{m}^{2}$ e foi projetado pelo escritório ZGF Architects em 2015. É composto de blocos sobrepostos verticalmente, com o total de 48 leitos (Figura 6).

O hospital referencial da pesquisa, o CIB, está localizado na região metropolitana de Campinas, no Estado de São Paulo, e foi fundado em 1978. É um hospital filantrópico e presta serviço à rede do SUS (80\%) e a convênios médicos $(20 \%)$. É especializado em oncologia e hematologia pediátricas, considerado um centro de referência mundial no tratamento de câncer infantil. O edifício ocupa $130.000 \mathrm{~m}^{2}$, com 77 leitos de internação (Figura 7).

O Hospital do CIB é composto de um edifício de três pavimentos com três alas cada pavimento, uma brinquedoteca em torno da qual estão dispostos seis blocos retangulares de um pavimento, um bloco de serviços de um pavimento, e uma área térrea provisoriamente ocupada pela UTI (Figura 8).

No CIB o cuidado humanizado acelera a recuperação do paciente com a presença contínua de acompanhante, de amigos e dos voluntários. Na brinquedoteca são realizadas atividades de entretenimento, oficinas de arte e apresentações teatrais. A sala de apoio pedagógico permite que o jovem dê continuidade a seus compromissos acadêmicos. A quimioterapia ambulatorial pediátrica foi recentemente reformada e é constituída de sete leitos e cinco poltronas, com 25 atendimentos/dia (Figura 9).

A humanização do cuidado e a adesão ao tratamento fundamentam-se no voluntariado, que fornece amparo aos pacientes e familiares, visando a sua valorização e dignidade, de acordo com a Lei nº 13.297/2016.

\section{Procedimentos metodológicos}

Os achados na revisão bibliográfica incentivaram a pesquisa na identificação dos principais fatores que determinam e contribuem para a ocorrência do fenômeno da humanização da arquitetura em centros de quimioterapia pediátrica. A revisão bibliográfica centrou-se em estudos recentes e nos conteúdos normativos nacionais, orientando a seleção dos estudos de caso analisados.

Foram feitas entrevistas com especialistas brasileiros, sendo seis semiestruturadas e duas nãoestruturadas com profissionais de diferentes formações, designados por A, B, C, D, E, F, G e H, sendo:

(a) 4 arquitetos especializados em arquitetura hospitalar; 
(b) 1 médico pediatra;

(c) 1 diretor de comissão de humanização Hospital Infantil Darcy Vargas (HIDV); e

(d) 2 voluntários.

Figura 6 - Centro de Câncer da Universidade do Arizona

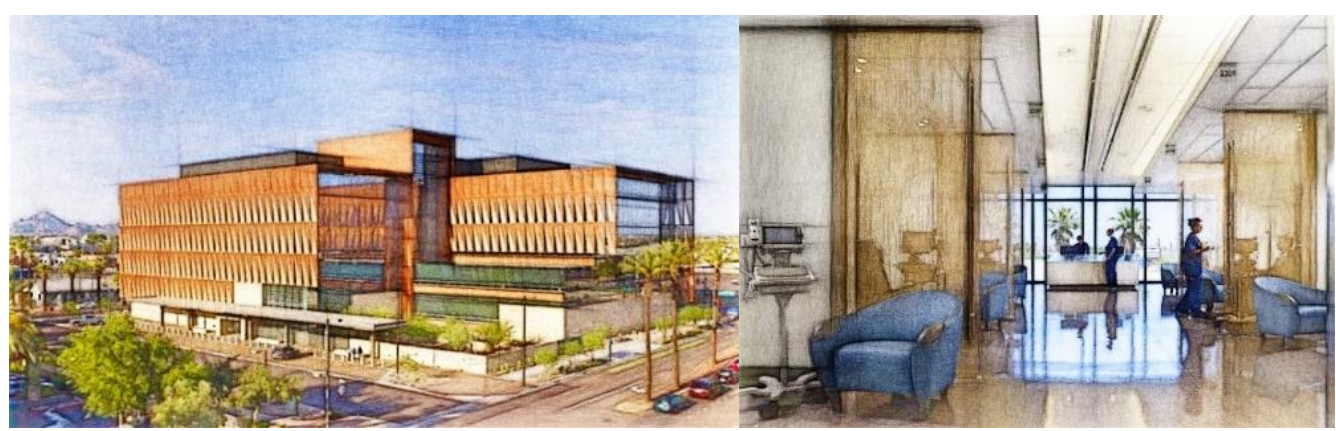

Fonte: releitura dos autores com base em University of Arizona Cancer Center / ZGF Architects (2019).

Figura 7- Hospital CIB

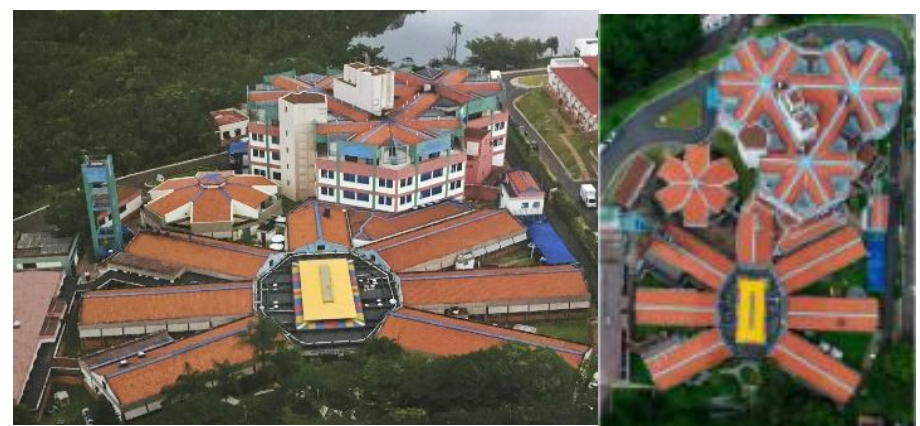

Fonte: Centro Infantil Boldrini (2020).

Figura 8 - Pavimento térreo do CIB

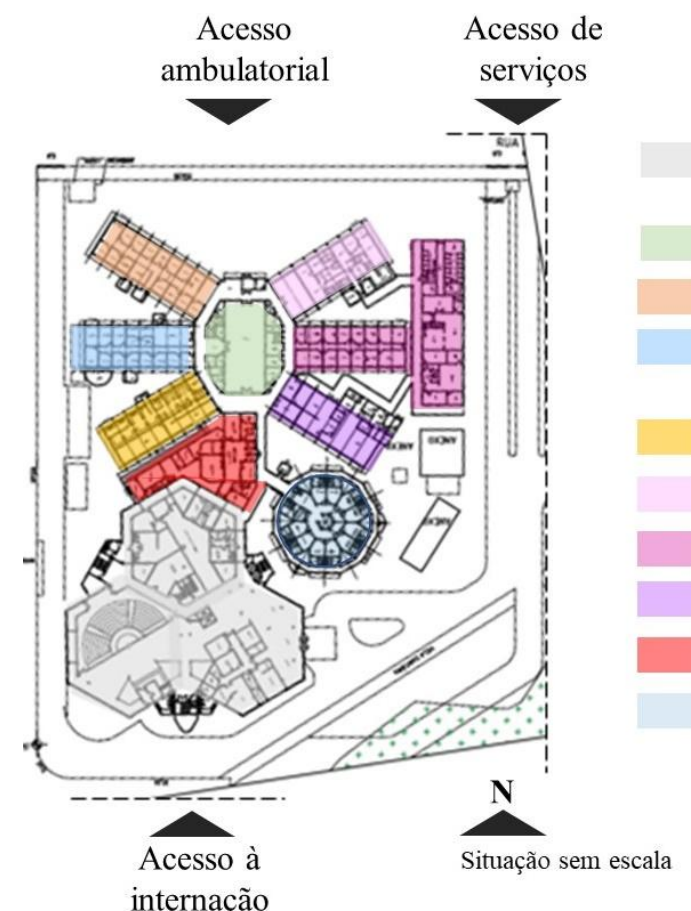

Internação, UTI em reforma, lanchonete e auditório

Brinquedoteca

Consultórios

Centro de quimioterapia ambulatorial, farmácia, nutrição, serviço social e psicologia SAME e laboratório

Refeitório e cozinha

TI, logística, depósito

Banco de sangue e almoxarifado

Centro cirúrgico

UTI provisória

184 Leitner, A. D.; Pina, S. M. 
Figura 9 - Centro de infusão pediátrica e brinquedoteca no CIB

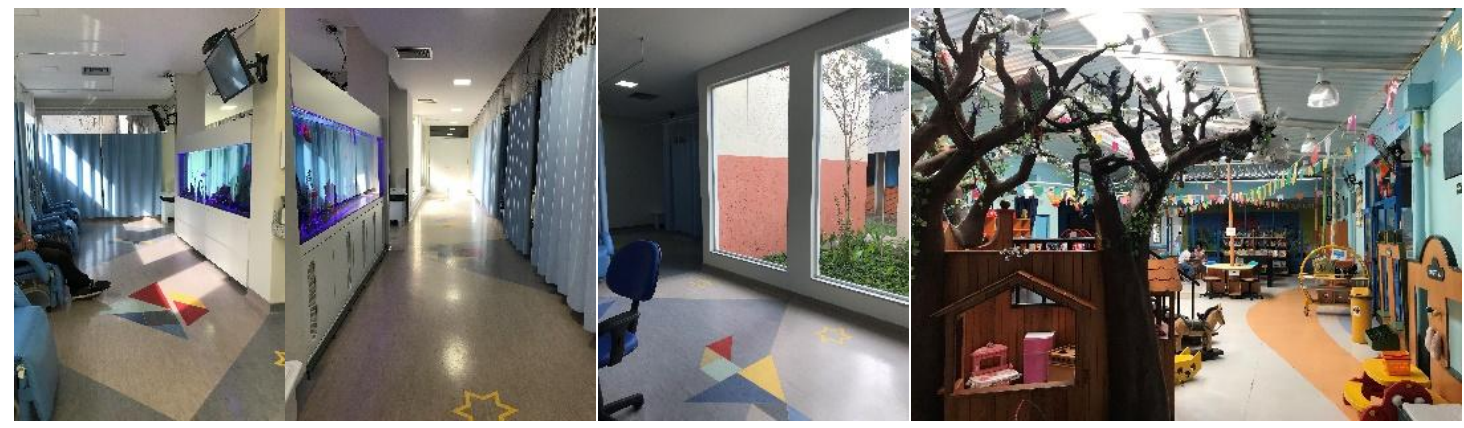

Para o CIB, no período de julho a setembro de 2019, foram aplicados os seguintes instrumentos de APO:

(a) levantamento do histórico de ocupação;

(b) estudo da setorização;

(c) análise do projeto de arquitetura;

(d) visitas de reconhecimento;

(e) vistorias técnicas/walkthrough e wayfinding;

(f) aplicação de checklist;

(g) registros visuais;

(h) 10 entrevistas semiestruturadas com pessoas-chave; e

(i) aplicação de 15 questionários e do Poema dos Desejos para 11 crianças pacientes de idades entre 3 e 12 anos.

Tais instrumentos foram selecionados por sua capacidade de resposta entre as atividades permitidas e aprovadas pela equipe de ética do hospital e da universidade ${ }^{2}$. O Poema dos Desejos (SANOFF, 1995) consistiu na dinâmica de grupo em que foi solicitado às crianças pacientes que expressassem por meio de desenhos seus desejos sobre o ambiente analisado. No CIB a apresentação da frase "Eu desejo que meu ambiente..." estimulou a realização dos desenhos.

\section{Resultados e discussão}

Os principais resultados obtidos foram organizados em três sessões principais, conforme segue.

\section{Considerações sobre os benchmarks}

Para os hospitais internacionais, a humanização dos ambientes de saúde é norteada pela preocupação em reduzir a tensão característica do ambiente hospitalar, melhorando as relações interpessoais dos usuários com a tríplice inclusão. A filosofia que corrobora o termo "ambiente de cura", condutora das ações de humanização atuais, permite estabelecer as prioridades que norteiam a organização e seus ambientes na busca da qualidade para a afirmação da vida.

Os hospitais analisados valorizam a hospitalidade com a promoção do cuidado centrado na família e com ambientes familiares às famílias. Os três hospitais americanos valorizam a ambiência interna, semelhante a um hotel ou spa, com destaque para o Nemours e para o Ann \& Robert H. Lurie Children's Hospital, que disponibilizam acomodação para os pais durante a internação. Uma questão central orientou o planejamento hospitalar dos ambientes e instalações, especialmente para o Hospital Infantil Nemours, "O que é melhor para as crianças?", preocupação que pode ser referência para hospitais semelhantes. Na perspectiva da arquitetura, destaca-se o uso de grandes lobbies, escadas rolantes na base dos edifícios, praças de alimentação, cafés, áreas de exposição, locais para esculturas aéreas e de outras obras de arte, instalações temáticas para crianças e áreas de recreação. Os ambientes destinados às equipes não assistenciais são

${ }^{2}$ Pesquisa aprovada pelo Comitê de Ética em Pesquisa, Parecer $n^{\circ} 3.380 .778 / 2019.0$ s participantes assinaram o termo de consentimento livre e esclarecido (TCLE). 
valorizados e separados das áreas sociais e de atendimento à saúde, com preocupação em prover áreas de descanso ao ar livre, considerando o estressea que são continuamente submetidos no atendimento aos pacientes e seus familiares.

O voluntariado é uma iniciativa relevante e tem importância cada mais crescente no cotidiano hospitalar. No caso dos hospitais internacionais estudados, a área destinada ao voluntariado abriga diversas organizações e inciativas, ocupando área equivalente à de um pronto-atendimento.

Entre as estratégias projetuais identificadas salienta-se o estímulo à curiosidade como no Suzhou Children's Hospital, por sua forma orgânica e volumetria lúdica; para os demais, a provocação à curiosidade se desenvolve em seu interior, com formas orgânicas que compõem os ambientes sociais e de atendimento à saúde e eventualmente algum reflexo nas fachadas pelo jogo de luzes coloridas nas janelas nos três hospitais pediátricos internacionais.

O wayfinding interno é favorecido em todos os hospitais analisados; nos pediátricos, com amplo uso de materiais coloridos e iluminação indireta e colorida. A iluminação promove a integração tecnológica funcional e divertida, e as fachadas são dinâmicas à medida que toques de luzes coloridas asseguram diversão. A ampla utilização de luzes, cores e materiais translúcidos são utilizados nos três hospitais pediátricos analisados. Nestes a preocupação se estende para o mobiliário colorido e com ergonomia adequada às faixas etárias. No Centro de Câncer da Universidade do Arizona, único hospital estudado que não é pediátrico, predominam as cores neutras no mobiliário e no acabamento em geral (Figura 6).

A valorização do paisagismo como estratégia de humanização está presente em todos os estudos de caso analisados, e os meios de valorização vinculam-se com os recursos disponíveis em cada região na qual os edifícios se inserem, como elemento inovador. Entre os aspectos de paisagismo valorizados elencam-se os jardins terapêuticos, os water gardens, os jardins de plantas medicinais, os sky gardens, e os jardins em subsolos que iluminam e ventilam o pavimento, pátios e terraços ajardinados. Na cultura chinesa é relevante o papel da natureza na cura, muito valorizado.

O recurso de ampla entrada de luz natural com grandes aberturas, que promove o contato com o meio externo e a valorização da vista para o exterior, é utilizado em todos os estudos de caso analisados. O Centro de Infusão de Câncer da Universidade do Arizona apresenta amplas aberturas para o exterior em todo o perímetro do edifício e exemplifica como a arquitetura pode contribuir para a preservação do ciclo circadiano dos usuários. O uso de iluminação indireta em circulações e como alternativa para os ambientes assistenciais, quando pertinente, reduz o incômodo gerado pela iluminação direta, sobretudo aos pacientes em leitos e macas que auxiliam também o wayfinding interno. A base ampliada com relação à torre nos três hospitais pediátricos permitiu a implantação do sky lobby,facilitando a iluminação natural dos ambientes que estão longe das fachadas. O Quadro 1, a seguir, elenca as principais características de humanização da arquitetura que norteiam os hospitais analisados.

Os documentos disponíveis do Centro de Câncer da Universidade do Arizona permitiram uma análise mais cuidadosa do centro de infusão. Nos hospitais pediátricos internacionais, os recursos de humanização identificados são aplicados convenientemente de maneira holística nos centros de infusão pediátricos, sendo também expandido para outros setores do edifício. A busca pelo conceito da tríplice inclusão, principal eixo da humanização em saúde, tem estimulado a concepção de espaços cada vez mais participativos, inclusive com a criação de comitês de pais de pacientes, de forma a assegurar o bem-estar dos colaboradores, pacientes e acompanhantes. 


\section{Quadro 1 - Síntese da humanização na arquitetura a partir da análise de benchmarks}

\begin{tabular}{|c|c|}
\hline \multirow{6}{*}{ Tríplice inclusão } & Ambientes de cura \\
\hline & Cuidado centrado na família \\
\hline & Promoção de ambientes familiares às famílias \\
\hline & Comitê familiar de pais e crianças \\
\hline & Hospitalidade \\
\hline & Voluntariado \\
\hline \multirow{7}{*}{$\begin{array}{l}\text { Aspectos físicos em } \\
\text { hospital pediátrico de } \\
\text { câncer }\end{array}$} & Estímulo à curiosidade \\
\hline & Volumetria lúdica (pipa) \\
\hline & Formas orgânicas no exterior e no interior \\
\hline & Wayfinding externo e interno \\
\hline & Acesso a múltiplas áreas externas \\
\hline & Quartos com acomodação para ambos os pais \\
\hline & Estruturas de apoio como cabeleireiro, lojas, etc. \\
\hline \multirow{4}{*}{$\begin{array}{l}\text { Aspectos físicos em } \\
\text { centro de infusão }\end{array}$} & Baias de atendimento não separadas ou separadas por cortinas ou divisórias \\
\hline & Grandes aberturas com vista para o exterior \\
\hline & Poltronas confortáveis para os acompanhantes \\
\hline & Uso de cores neutras em ambiente para adultos \\
\hline \multirow{6}{*}{ Ambientes sociais } & Praça de alimentação e cafés \\
\hline & Ambiência interna semelhante a um hotel \\
\hline & Grande lobby \\
\hline & Uso de escadas rolantes \\
\hline & Áreas de exposição \\
\hline & Instalações temáticas e esculturas aéreas \\
\hline \multirow{3}{*}{ Interação } & Instalações interativas \\
\hline & Áreas de recreação \\
\hline & Palcos e espaços para apresentações infantis \\
\hline \multirow{3}{*}{$\begin{array}{l}\text { Ergonomia / } \\
\text { Mobiliário }\end{array}$} & Mobiliário e equipamentos adequados às faixas etárias \\
\hline & Mobiliário colorido e/ou com cores neutras \\
\hline & Distrações positivas ativas (ex. jogos e brincadeiras) \\
\hline \multirow{8}{*}{ Paisagismo } & Sustentabilidade e eficiência energética \\
\hline & Valorização do paisagismo \\
\hline & Jardins terapêuticos (healing gardens) \\
\hline & Water gardens \\
\hline & Jardins de plantas medicinais \\
\hline & Sky garden \\
\hline & Jardins em subsolos \\
\hline & Pátios e terraços ajardinados \\
\hline \multirow{6}{*}{$\begin{array}{c}\text { Iluminação e } \\
\text { ventilação naturais }\end{array}$} & Ampla entrada de luz natural \\
\hline & Valorização da vista para o exterior \\
\hline & Contato com meio externo \\
\hline & Preservação do ciclo circadiano \\
\hline & Luzes indiretas em ambientes assistenciais quando pertinentes \\
\hline & Sky lobby \\
\hline \multirow{6}{*}{$\begin{array}{l}\text { Integração } \\
\text { tecnológica }\end{array}$} & Integração tecnológica pela luz, funcional e divertida \\
\hline & Ampla utilização de luzes e cores \\
\hline & Fachada e ambientes dinâmicos com luzes coloridas \\
\hline & Diversão por toques de luzes coloridas \\
\hline & Uso de cores na fachada \\
\hline & Entrada de luz natural pela cobertura translúcida do volume basal \\
\hline
\end{tabular}

\section{Considerações sobre as entrevistas com especialistas e voluntários}

As entrevistas com especialistas e voluntários objetivaram ampliar o entendimento do tema da pesquisa, humanização da arquitetura hospitalar em ambientes de quimioterapia pediátrica, alinhada ao conceito da tríplice inclusão. Para tanto, foi elaborado um roteiro de entrevistas contendo dez perguntas sobre os seguintes aspectos:

(a) como o estudo prévio dos ambientes de quimioterapia pediátrica pode colaborar com o programa de necessidades e com a execução do projeto arquitetônico sob a ótica da humanização; 
(b) no atendimento às expectativas da equipe assistencial (médicos, corpo de enfermagem, técnicos, psicólogos, entre outros), das crianças pacientes e de seus acompanhantes, como tornar a arquitetura de centros de infusão mais eficaz e mais amigável aos usuários;

(c) como é considerada a inter-relação do centro de quimioterapia pediátrica com os demais setores de um hospital no projeto arquitetônico;

(d) quais tipos de necessidades ambientais e comodidades que as crianças em tratamento quimioterápico experimentam e que suscitam o conforto e o acolhimento, estimulando seu retorno às sessões;

(e) quais são as estratégicas ou técnicas de abordagem do ponto de vista da criança paciente;

(f) como os ambientes de quimioterapia pediátrica são projetados centrados no bem-estar do acompanhante;

(g) como o estudo de centros de quimioterapia pediátrica pode ser associado a privacidade, estresse, satisfação, conforto e esperança do paciente no tratamento de quimioterapia;

(h) quais são os benefícios da quimioterapia ambulatorial no estímulo à desospitalização;

(i) como pesquisas multidisciplinares como o design e a APO fazem parte da rotina do arquiteto no Brasil e qual a importância de um modelo participativo dessas equipes para o projeto de centros de quimioterapia pediátrica; e

(j) no cenário de intensa dinâmica social e tecnológica, quais são as tendências possíveis de se detectar com reflexos no programa de necessidades, no projeto arquitetônico e nas expansões de centros de quimioterapia pediátrica.

Foram realizadas seis entrevistas com profissionais correlacionados ao tema, sendo 4 arquitetos, 1 médico e 1 diretor de humanização. Além deles, foram entrevistados 2 voluntários. Os entrevistados foram designados por A, B, C, D, E, F, G e H.

$\mathrm{O}$ arquiteto A tem graduação em Arquitetura e Urbanismo e mestrado em Engenharia Civil pela Universidade Estadual de Campinas e já atuou no Centro Infantil Boldrini (CIB).

O arquiteto B é graduado em Arquitetura e Urbanismo pela Universidade Presbiteriana Mackenzie. Tem mestrado em Saúde Coletiva pela Faculdade de Ciências Médicas da Unicamp e doutorado pela Faculdade de Engenharia Civil, Arquitetura e Urbanismo da Unicamp. Desenvolveu consultoria técnica no Programa das Nações Unidas para o Desenvolvimento (PNUD/ONU), tendo atuado no Ministério da Saúde, com a Política Nacional de Humanização da Gestão e Atenção no Sistema Único de Saúde (SUS) para o tema da Ambiência na Saúde e Arquitetura Hospitalar.

$\mathrm{O}$ arquiteto $\mathrm{C}$ tem graduação em Arquitetura e Urbanismo, foi professor do Departamento de Produção e Operações Empresariais da Escola de Administração de Empresas de São Paulo, da Fundação Getúlio Vargas (FGV), professor do Programa de Estudos Avançados em Administração Hospitalar e da Saúde (Proahsa) e professor da Pós-Graduação do Centro Paulista de Economia em Saúde da Unifesp. Foi fundador e primeiro presidente da Associação Brasileira para o Desenvolvimento do Edifício Hospitalar (ABDEH). É autor e coautor de livros sobre arquitetura hospitalar.

O arquiteto D tem graduação, mestrado e doutorado em Arquitetura e Urbanismo pela Faculdade de Arquitetura e Urbanismo da Universidade Federal do Rio de Janeiro (UFRJ). Atualmente, é professor convidado da Universidade Cidade de São Paulo. Tem experiência na área de Arquitetura e Urbanismo, com atuação nos temas serviços de saúde, humanização e arquitetura hospitalar, postos de saúde, ambiente e arquitetura moderna.

O médico pediatra E tem graduação e residência em Pediatria pela Faculdade de Medicina da Universidade de São Paulo (USP). Fez pós-graduação lato sensu em Gestão em Saúde pela Fundação Dom Cabral e especialização em Administração Hospitalar Sistemas de Saúde pela FGV. É diretor técnico do Departamento de Saúde no Hospital Infantil Darcy Vargas (HIDV), da Secretaria Estadual de Saúde de São Paulo.

O entrevistado F é diretor da comissão de humanização do HIDV, onde desenvolve e coordena as ações do grupo de voluntários do hospital, incluindo as demais ações de humanização. Os voluntários $\mathrm{G}$ e $\mathrm{H}$ possuem graduação em Administração de Empresas pela FGV. 


\section{Entrevistado A}

O entrevistado A identifica o uso dos dois tipos de ambientes conforme o estágio de tratamento do paciente. No setor ambulatorial, as baias de atendimento de $7 \mathrm{~m}^{2}$ são separadas por cortinas ou divisórias. Baias abertas ou fechadas são usadas conforme o estado emocional da criança paciente. Há dois tipos de mobiliário:

(a) camas para os pacientes em tratamento prolongado; e

(b) poltronas reclináveis para atendimento rápido.

A instalação de janelas sobre baixo peitoril permite a visualização pelo paciente acamado da área externa, e um aquário permite distração passiva às crianças (em destaque na Figura 10).

A presença da brinquedoteca nas proximidades do ambulatório facilita o lazer aos pacientes. Entre as implicações da oncologia pediátrica avançada, reserva-se um pavimento próprio para pacientes juvenis crônicos, com distrações digitais e pinturas em grafite nas acomodações. No Brasil, o Estatuto da Criança e do Adolescente (ECA), Lei $\mathrm{n}^{\mathbf{0}}$ 8.069, de 1990, considera criança a pessoa de até 12 anos de idade incompletos e define a adolescência como a faixa etária de 12 a 18 anos de idade (art. $2^{\circ}$ ); em casos excepcionais e quando disposto na lei, o estatuto é aplicável até os 21 anos de idade (arts. 121 e 142). A mais recente inovação é a criação do centro de reabilitação profissional e inserção social com oficinas profissionalizantes de costura e teatro, entre outras (Figura 11).

Para fomentar o processo de projeto de ambientes para os pacientes em centros pediátricos de infusão, o arquiteto A recomenda conversas com grupos de voluntários e especialmente com os profissionais da enfermagem. Estes últimos, sob seu ponto de vista, podem contribuir para a compreensão das necessidades dos pacientes e, sobretudo, das demandas referentes à execução das próprias tarefas. Já o grupo de voluntários pode indicar demandas espaciais para a realização de ações humanizadas com os pacientes, incentivando condutas e arranjos ambientais para sua inclusão, uma vez que suas ações incluem a realização de trabalhos manuais, doações, bazares, visitas de apoio aos pacientes e familiares, e atividades sociorrecreativas.

Figura 10 - Planta e imagem da quimioterapia pediátrica - CIB

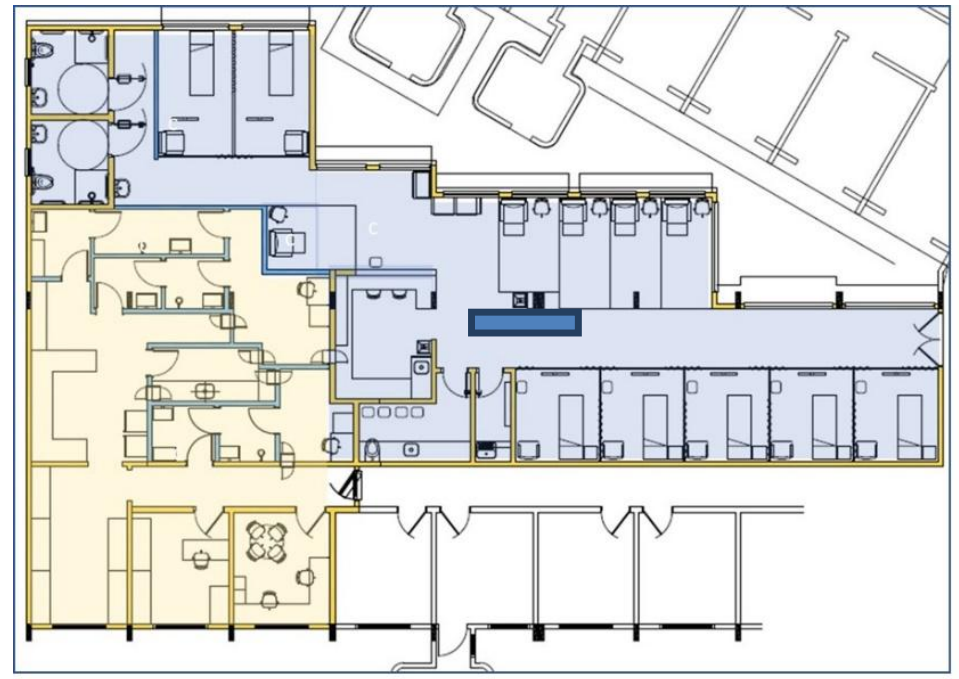

Situação sem escala

Fonte: adaptada do acervo do entrevistado arquiteto A.

Centro de infusão

Farmácia 
Figura 11 - Quarto para pacientes juvenis e reabilitação - CIB

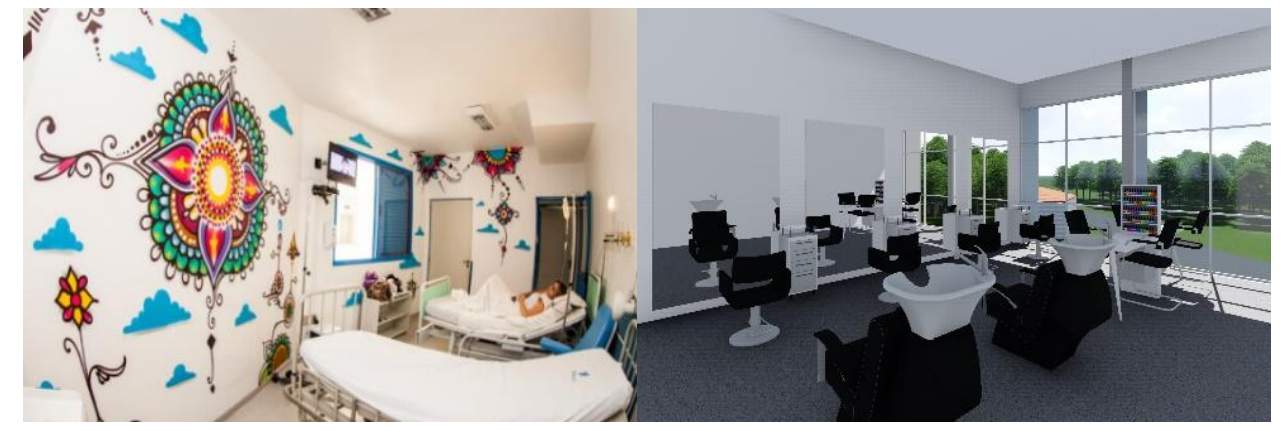

Fonte: acervo dos autores e adaptada do entrevistado arquiteto $\mathrm{A}$.

\section{Entrevistado B}

Para o arquiteto B, o principal condicionante das adequações de áreas assistenciais da saúde é baseado nos três princípios da humanização: a indissolubilidade da gestão e da atenção; a tríplice inclusão; e a valorização do trabalho. A ambiência deve propiciar arranjos que permitam a singularização do cuidado humanizado, criando possibilidades lúdicas no box da quimioterapia e nos caminhos percorridos pela equipe de cuidado integral. No processo de projeto de edifícios preexistentes, o envolvimento de enfermeiros, gestores, trabalhadores e arquitetos permite identificar melhor as demandas do paciente. Trata-se de uma roda de conversa que estimula o processo participativo dos usuários. O entrevistado reforça que as normas exigem o mínimo necessário de área, mas não o recomendável.

\section{Entrevistado C}

Para o arquiteto $\mathrm{C}$, a quimioterapia está sendo gradativamente encaminhada para o ambiente ambulatorial. Antes realizada no leito, o tratamento tende a ser realizado na casa do paciente, o que favorece a desospitalização. É esperado que o ambulatório não aumente, uma vez que os avanços médicos têm permitido que as consultas sejam mais acertadas devido à inteligência artificial e ao PEP.Segundo ele, cabe ao arquiteto ter visão estratégica e antecipar o futuro pelo olhar das inovações na saúde. $\mathrm{O}$ foco nessa forma de gestão deve priorizar o cuidado com a saúde, e não a doença, de modo a prevenir possíveis enfermidades.

Para o entrevistado, a elaboração do plano diretor hospitalar está associada ao entendimento dos processos que se encerram no atendimento assistencial. O plano diretor hospitalar é uma nova ferramenta de gestão de projeto, e cabe ao arquiteto entendê-lo para que seja otimizado, sobrepondo os usos ambientais. No modelo participativo, os atores do processo de projeto devem ser estimulados a desenvolveruma visão menos imediatista. Considera imprescindível a formação de um comitê do futuro que os estimule ao exercício do empreendedorismo e da inovação, com visão do futuro da saúde e do ambiente da saúde.

\section{Entrevistado D}

O arquiteto D reforça a valorização da arte no ambiente hospitalar como exemplo de humanização. Comenta a iniciativa do Hospital Federal da Lagoa (HFL), referência em oncologia pediátrica, pelo uso do jardim externo com atividades de zooterapia com pôneis. A iniciativa exemplifica como o contato com os animais fora das enfermarias ajuda a libertar a criança do estigma da doença: nos jardins, em contato com as plantas, sentindo o ar puro, derrubam-se mitos como o de que a criança hospitalizada não pode brincar, não pode pisar no chão. Outros projetos de humanização estimulam o sistema imunológico e potencializam o restabelecimento e a recuperação da saúde física, mental e social, como os contadores de histórias e a meditação.

O ambulatório deve propiciar a confraternização das crianças. A distribuição de mesinhas infantis para refeição e para a realização de trabalhos manuais, o acesso a terraços, a iluminação natural, a percepção do dia e da noite, para que as crianças pacientes mantenham o ritmo circadiano, contribuem sobremaneira para o processo de cura. O entrevistado cita o exemplo de ambiente de quimioterapia pediátrica com leitos e poltronas para medicação, área para brincar e acesso a computadores para os acompanhantes (Figura 12). 
Figura 12 - Quimioterapia ambulatorial - HFL

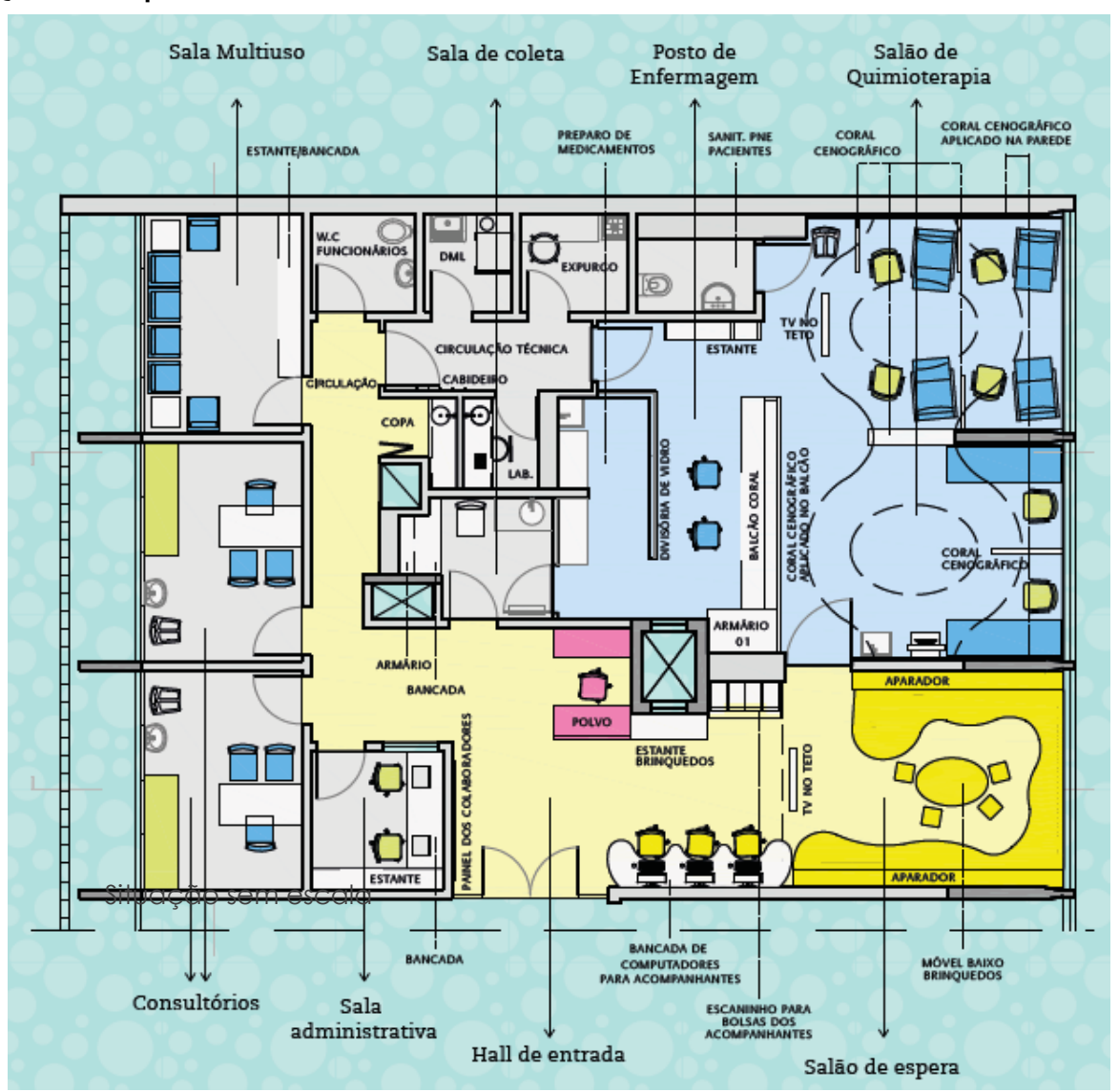

Fonte: adaptada de Instituto Desiderata (2015).

Para os acompanhantes, houve a inclusão de armário para guardar pertences e local para interagirem com os demais acompanhantes. Um local para café dentro da quimioterapia é aconselhável, assim como sala para parlatório, haja vista a troca de experiências pela equipe assistencial. O arquiteto D propõe que pacientes juvenis sejam encaminhados para outro setor de quimioterapia ambulatorial e ressalta a lacuna de pesquisas sobre ambientes de quimioterapia destinados a esse público juvenil.

\section{Entrevistados E e F}

O entrevistado E é médico do HIDV, referência no atendimento infantil para doenças de alta complexidade da rede pública. A comissão de humanização do hospital tem suas ações pautadas na PNH, é composta de 14 colaboradores, e sua estrutura física integra a sala administrativa, a sala de ouvidoria e a sala da acolhida. Atualmente, 44 parceiros se revezam em mais de 50 projetos de humanização.

Segundo o diretor de humanização, entrevistado F, a humanização é uma ferramenta de gestão que transforma a cultura institucional e motiva os usuários. Para o entrevistado E, as atividades de humanização têm pouco impacto nos ambientes, pois são realizadas em espaços existentes ou adaptados. Para a maioria delas, não é necessário ambiente próprio, e os usos são alternados, como aos domingos, quandoatividades de pintura e de teatro são realizadas no anfiteatro. Cantores e contadores de histórias realizam visitas nos quartos de internação. Alguns ambientes sofrem pequenas adequações, como a sala de exames de imagens adesivada com temática infantil e o jardim terapêutico (Figura 13).

No ambiente de quimioterapia pediátrica do HIDV, uma mesa central permite atividades de desenho. Os pais acompanham os filhos, mas não há ali ações de humanização. As baias não são separadas, tampouco há cortinas de separação (Figura 14). O HIDV espalha brinquedos nos trajetos realizados pelas crianças e nas salas de estar, o que colabora para diminuir a ansiedade na espera para os exames. Na parte externa, um parquinho distrai as crianças pacientes, e há uma brinquedoteca em cada pavimento assistencial.

Como exemplos de ambientes humanizados específicos destacam-se os consultórios odontológicos para funcionários e para as crianças pacientes, com mobiliário apropriado; o tratamento das mucosites causadas 
pelo câncer não é obrigatório em hospitais públicos. Destaca-se também a casa do voluntariado, edificada em parte do estacionamento do hospital, pré-fabricada e irregular, onde está instalado o bazar.

\section{Entrevistados voluntários G e H}

Entre as ações do voluntário $G$ estão as visitas semanais de cães de estimação e a condução do plano de coleta de água pluvial no HIDV. O entrevistado H é voluntário no Grupo de Apoio ao Adolescente e à Criança com Câncer (Graacc), instituição social que atende mais de 3.500 crianças e adolescentes com câncer por ano. $\mathrm{O}$ voluntariado é um dos principais pilares que sustentam os serviços e reúne mais de 500 pessoas.

$\mathrm{O}$ entrevistado $\mathrm{H}$ sugere que no local da quimioterapia seja incorporada a prática do brincar, favorecendo o riso e o bem-estar. No ambiente da quimioteca, os atendimentos são dedicados ao resgate da autoestima, realizados por equipe de enfermeiros, psicólogos, assistentes sociais, fonoaudiólogos, terapeutas ocupacionais e endocrinologistas. $\mathrm{O}$ espaço deve ser colorido, com brinquedos e livros, e pouco lembrar um ambiente hospitalar. A quimioteca disponibiliza postos com poltrona ou cama para o paciente, e cadeira para o acompanhante. O ambiente dispõe de material pedagógico infanto-juvenil adequado à fase de desenvolvimento em que se encontram as crianças.

Os resultados das entrevistas, tanto com especialistas quanto voluntários, reforçam a importância das ações humanizadoras nos diversos ambientes de tratamento pediátrico. No cenário brasileiro, a humanização da arquitetura possui diversos mecanismos para transformar o edifício da saúde em ambiente mais saudável para os usuários, com foco na tríplice inclusão. Contudo, as ações apresentadas referem-se a ambientes pontuais, enquanto não é recorrente sua abordagem no edifício como um todo, especialmente na volumetria. No hospital brasileiro, o voluntariado não tem área relevante designada para ele.

As entrevistas semiestruturadas e não estruturadas, de caráter exploratório, propiciaram liberdade e flexibilidade às respostas. Os entrevistados ficaram à vontade para contribuir para além do roteiro estabelecido e ampararam parte das afirmações com exemplos da realidade. O Quadro 2 apresenta a síntese das entrevistas em centros de infusão pediátricos segundo os entrevistados.

Figura 13 - Humanização em sala de exames e jardim terapêutico do HIDV

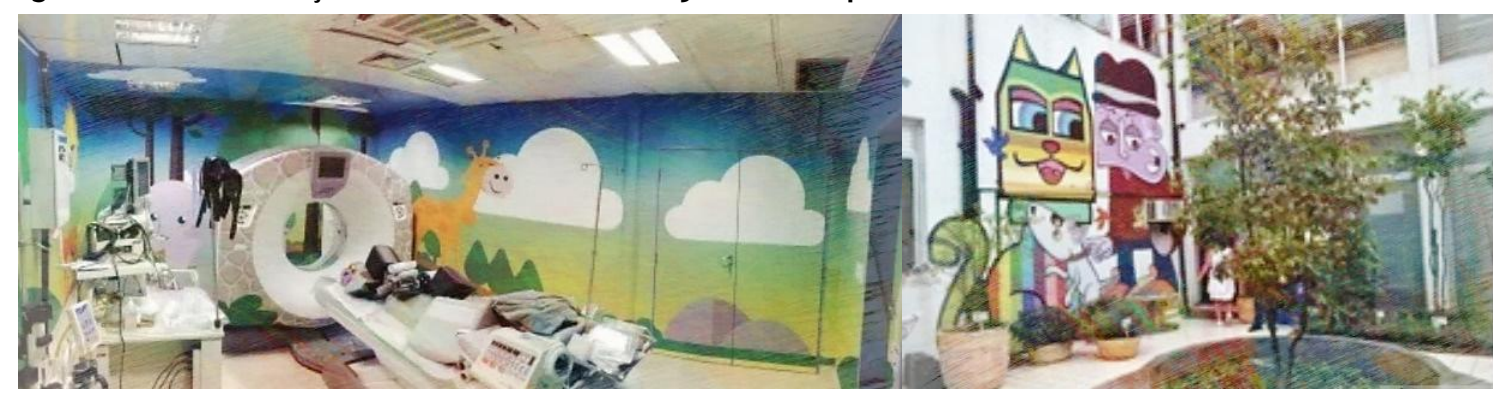

Fonte: releitura dos autores a partir de Magalhães (2018).

Figura 14 - Quimioterapia ambulatorial do HIDV

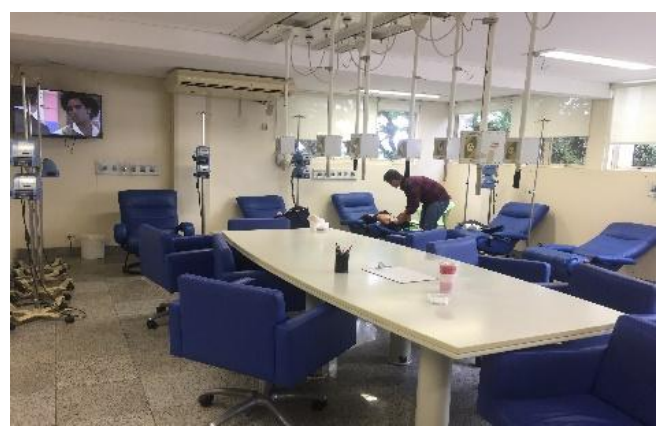

192 Leitner, A. D.; Pina, S. M. 


\section{Quadro 2 - Síntese da humanização na arquitetura a partir dos entrevistados}

\begin{tabular}{|c|c|}
\hline \multirow{6}{*}{ Tríplice inclusão } & Cuidado da saúde, e não da doença \\
\hline & Modelo participativo, visão menos imediatista \\
\hline & Cuidado integral com foco na rede de cuidado do paciente \\
\hline & Indissolubilidade da gestão e da atenção \\
\hline & Cuidado centrado na família \\
\hline & Voluntariado \\
\hline \multirow{8}{*}{$\begin{array}{l}\text { Aspectos físicos em } \\
\text { centro de infusão } \\
\text { pediátrico }\end{array}$} & Baias de atendimento não separadas ou separadas por cortinas ou divisórias \\
\hline & Separação de adultos e crianças pacientes \\
\hline & Opções de mobiliário para o paciente: camas, poltronas reclináveis, berços \\
\hline & Grandes aberturas com vista para o exterior \\
\hline & Poltronas confortáveis para os acompanhantes \\
\hline & Local para acompanhantes trocarem experiências \\
\hline & Quimioteca com material pedagógico \\
\hline & Local para atividades lúdicas \\
\hline \multirow{6}{*}{$\begin{array}{l}\text { Aspectos físicos em } \\
\text { hospital pediátrico de } \\
\text { câncer }\end{array}$} & Separação espacial para adolescentes crônicos \\
\hline & Distrações positivas com pinturas joviais nas acomodações \\
\hline & Valorização de cenários que a criança paciente vivencia \\
\hline & Inovação: centro de reabilitação profissional e inserção social \\
\hline & Inovação: academia de reabilitação pediátrica \\
\hline & Inovação: implantação de consultório odontológico para pacientes \\
\hline \multirow{3}{*}{$\begin{array}{c}\text { Paisagismo e áreas } \\
\text { externas }\end{array}$} & Jardim externo, jardim terapêutico \\
\hline & Playground \\
\hline & Zooterapia (ex.: borboletário, visitas de cães e equinos) \\
\hline \multirow{3}{*}{ Ergonomia / Mobiliário } & Mobiliário e equipamentos adequados às faixas etárias \\
\hline & Armário para guarda de pertences \\
\hline & Distrações passivas (ex.: aquário, televisão, etc.) \\
\hline \multirow{3}{*}{$\begin{array}{l}\text { Ambientes sociais e de } \\
\text { interação }\end{array}$} & Valorização da arte em ambientes hospitalares com murais \\
\hline & Salas de recreação, brinquedotecas \\
\hline & Atividade de pintura e teatro em anfiteatro \\
\hline Iluminação & Fachadas envidraçadas \\
\hline
\end{tabular}

O cuidado centrado na família é conceito recorrente entre os entrevistados brasileiros, mas ainda não se identificam ambientes destinados aos familiares. O cuidado com a saúde em sobreposição ao cuidado com a doença se revela entre os entrevistados, mas o conceito de "ambientes que curam" ainda é pouco incorporado na prática do projeto.

As diversas alternativas de mobiliário, em atendimento às necessidades das crianças pacientes de acordo com a fase de tratamento e com sua idade, demonstram ser apropriadas.

Ficou evidente a necessidade de concepção de ambientes de quimioterapia dedicados às necessidades dos pacientes juvenis, que demandam atenção com a privacidade e outras estratégias de humanização do ambiente que auxiliem e preparem para a transição com a fase adulta. Sempre que possível, os recursos de humanização na arquitetura devem coincidir com as facilidades e recursos disponíveis no edifício e no entorno imediato, associando-se às inovações da arquitetura.

Ainda é incipiente a aplicação dos recursos tecnológicos de iluminação pela integração da luz de maneira funcional e divertida, os quais poderiam ser mais bem explorados, além do incentivo às grandes aberturas para entrada de luz natural. A incorporação da questão do bem-estar e do brincar para ambientes pediátricos revela a importância das distrações positivas no setor, como ambientes interativos que permitam a realização de atividades individuais e em grupo, favorecendo o acolhimento. A brinquedoteca identificada no estudo de caso é exemplo de referência nesse aspecto.

Para a adoção da zooterapia, pela qual os animais são facilitadores do resgate parcial da rotina do mundo exterior do paciente, os ambientes de saúde devem considerar as diversas oportunidades de integração do paciente com as áreas externas, como jardins e parques.

Por fim, embora o voluntariado venha ocupando papel de destaque na atenção e cuidado hospitalar, existe ainda pouca repercussão na arquitetura, como a implantação de ambientes específicos destinados a tais trabalhos e pessoas. Reforça-se a importância da inclusão desse grupo de trabalhadores e a realização de 
entrevistas para ampliar o conhecimento sobre as atividades desenvolvidas e suas demandas para projetos futuros.

As considerações sobre o processo de projeto revelam a importância do modelo participativo de equipe multidisciplinar que inclua representantes da humanização. Incentiva-se a compreensão pelo arquiteto do processo assistencial para a concepção do projeto arquitetônico, como ferramenta de projeto. A constituição de um comitê do futuro, composto de profissionais do setor com visão estratégica e empreendedora que atente às inovações e às tendências da medicina, revela sua importância a despeito da opinião dos colaboradores que tratam das questões espaciais do dia a dia.

\section{Achados da pesquisa de campo no CIB}

Sobre os resultados da aplicação do Poema dos Desejos, das 11 crianças, 10 desejavam estar na brinquedoteca e no parquinho, enquanto apenas 1 preferia estar fora do ambiente hospitalar. Os 10 desenhos realizados representaram atividades realizadas na brinquedoteca, mostrando ser ela o ambiente preferido de permanência das crianças pacientes. A importância desse ambiente se refere ao fato de ser o principal local do hospital que permite o livre-brincar, de dimensões generosas e de localização acolhedora, onde as crianças pacientes têm opções de escolha e estão livres do comando em atenção ao tratamento (Figura 15).

Os desenhos não contemplaram a proposição de que o ambiente representado pudesse ser melhorado, mostrando a satisfação dos aspectos físicos por parte das crianças pacientes. Cabe ressaltar que o CIB é o único hospital dentre os apresentados que possui a brinquedoteca no centro dos setores assistenciais (Figura 6), o que facilita seu acesso em todas as etapas de atendimento, de onde a criança paciente estiver e com área expressiva, semelhante a qualquer um desses setores. Os demais hospitais apresentam estruturas recreativas menores, distribuídas pelos setores onde a criança paciente se desloca, o que também ocorre no CIB. Ainda que o CIB tenha sido concebido em 1978, as contínuas adequações a que é submetido - como a pavimentação e a cobertura da área que se transformou em brinquedoteca - fazem dele um hospital atualizado com as premissas de humanização da arquitetura.

As entrevistas ampararam o conhecimento sobre as instalações, sobre o funcionamento do edifício e de seus setores, sobre as ações do voluntariado, do corpo assistencial da saúde, sobre a importância da classe hospitalar (BRASIL, 2002) e da concepção de ambiente adequado, bem como as ações da brinquedoteca, instalação obrigatória pela Lei n 11.104, de 21 de março de 2005.

As entrevistas realizadas em campo sobre a humanização da arquitetura hospitalar em ambientes de quimioterapia pediátrica seguiram um roteiro, contendo onze perguntas sobre aspectos como argumento ambiental principal, arquitetura mais humanizada, relação da quimioterapia com o hospital como um todo, necessidades ambientais dos pacientes infantis, demandas qualitativas dos pacientes infantis, modelos participativos de projeto em hospitais e tendências futuras em centros de quimioterapia pediátrica. Foram entrevistados 9 colaboradores (enfermagem, manutenção, TI, serviço social, pedagogia e psicologia) e 1 voluntário, complementando-se com a aplicação de questionários para 5 acompanhantes e 1 paciente adulto, o que totalizou 10 entrevistas e 15 questionários.

Figura 15 - Brinquedoteca e exemplo do Poema dos Desejos

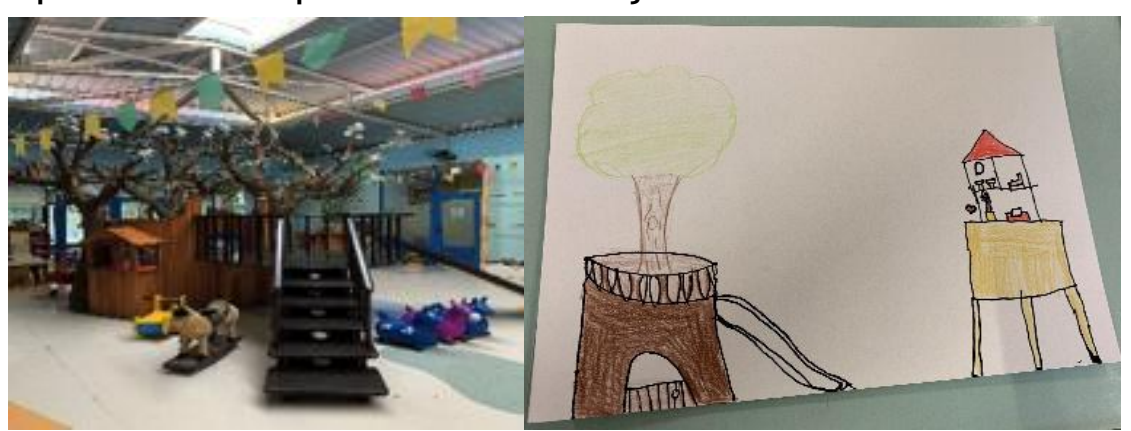

194 Leitner, A. D.; Pina, S. M. 
A tabulação dos questionários aplicados no CIB permitiu sintetizar as informações pontuadas ${ }^{3}$ pelos participantes:

(a) o principal argumento ambiental para a concepção de ambiente de quimioterapia ambulatorial infantil apresenta destaque para a brinquedoteca no setor e para o acolhimento dos colaboradores, ao atendimento humanizado, ao trabalho da assistência médica e à presença dos familiares;

(b) a arquitetura de ambiente de quimioterapia ambulatorial é mais humanizada pela valorização do trabalho dos colaboradores com aplicação de terapias alternativas e apoio psicológico;

(c) pelo atendimento prazeroso aos familiares, identificando empatia entre paciente, pais e colaboradores;

(d) pela promoção do livrebrincar;

(e) pela distribuição de brinquedos nos setores assistenciais;

(f) pela promoção de adequações;

(g) a grande maioria dos respondentes não identifica intersecções relevantes de fluxos indesejáveis;

(h) a ocorrência das necessidades e comodidades ambientais experimentadas em quimioterapia ambulatorial mais frequentes se dá por meio de TV, música e vista arborizada;

(i) as estratégias de abordagem da criança paciente mais frequentes ocorrem por meio do trabalho dos voluntários, das psicólogas, da linguagem apropriada à idade e da promoção do livrebrincar;

(j) os recursos recorrentes para que os ambientes sejam centrados na família se expressam no ambiente confortável para os acompanhantes, o que facilita a interação entre paciente e acompanhante, internet e alimentação;

(k) é possível associar o estudo de centros de quimioterapia ambulatorial a privacidade, estresse, satisfação, conforto e esperança do paciente no tratamento considerando o bom uso das instalações físicas, a privacidade pelas baias individualizadas, banheiros separados, e o resultado do conjunto promovendo a socialização;

(1) os benefícios da quimioterapia ambulatorial ainda não colaboram com a desospitalização;

(m) o estudo de ambientes de quimioterapia pediátrica pode ser adotado para a gestão da qualidade desse tipo de ambiente da saúde, sendo a reforma da quimioterapia ambulatorial a grande referência para a melhora constante do hospital;

(n) não há ainda identificação clara da importância da atuação de um modelo participativo das equipes interdisciplinares para o projeto de centros de quimioterapia pediátrica; e

(o) ainda não são facilmente identificadas as tendências possíveis de reflexos no programa de necessidades, no projeto arquitetônico e nas expansões em centros de quimioterapia pediátrica.

A pesquisa de campo totalizou as ponderações constantes no Quadro 3.

O entendimento da humanização no ambiente de quimioterapia pediátrica do CIB pressupôs a análise da contextualização do hospital, do setor em estudo em si, e da inter-relação da quimioterapia ambulatorial com os principais espaços que sobre ele interferem. Parte dos resultados advém da opinião de acompanhantes e pacientes do SUS, que não dispõem dos mesmos serviços em suas cidades de origem; são pessoas extremamente gratas pelo atendimento recebido e consideram, em sua maioria, o atendimento excepcional. Para a questão 8, sobre desospitalização, nota-se que os entrevistados, em sua maioria, desconhecem o significado do termo, o que sugere que os dados devam ser estudados com mais profundidade.

\section{Considerações finais}

A pesquisa apresentou um quadro recente e atualizado da humanização em ambientes de quimioterapia ambulatorial pediátrica e mostrou que seu pleno entendimento deve considerar a inter-relação com os setores afins e a contextualização desse ambiente no edifício como um todo.

${ }^{3}$ Apresenta a maior concentração entre as respostas obtidas. O relatório final da pesquisa de pós-doutorado apresenta as demais
respostas. respostas. 
Quadro 3 - Síntese da humanização da quimioterapia ambulatorial no CIB

\begin{tabular}{|c|c|}
\hline \multirow{4}{*}{ Tríplice inclusão } & $\begin{array}{l}\text { Cuidado da saúde, e não da doença } \\
\text { Cuidado integral com foco na rede de cuidado do paciente }\end{array}$ \\
\hline & Atendimento prazeroso aos familiares \\
\hline & Hospitalidade (acomodação e alimentação para acompanhantes) \\
\hline & Voluntariado \\
\hline \multirow{6}{*}{$\begin{array}{l}\text { Aspectos físicos } \\
\text { em hospital } \\
\text { pediátrico de } \\
\text { câncer }\end{array}$} & Separação espacial para adolescentes crônicos \\
\hline & Distrações positivas com pinturas joviais nas acomodações \\
\hline & Valorização de cenários que a criança paciente vivencia \\
\hline & Atividade escolar para pacientes \\
\hline & Realização de exames médicos na instituição \\
\hline & Emprego de cores alegres \\
\hline \multirow{3}{*}{$\begin{array}{l}\text { Aspectos físicos } \\
\text { em centro de } \\
\text { infusão pediátrico }\end{array}$} & Boxes individualizados, privacidade \\
\hline & Grandes aberturas com vista para o exterior \\
\hline & Poltronas confortáveis para o acompanhante \\
\hline & Brinquedoteca (promoção do livre brincar) \\
\hline \multirow[t]{2}{*}{ Interação } & Ambiente para socialização \\
\hline & Distribuição de brinquedos nos setores assistenciais \\
\hline \multirow{4}{*}{$\begin{array}{l}\text { Ergonomia / } \\
\text { Mobiliário }\end{array}$} & Mobiliário e equipamentos adequados às faixas etárias \\
\hline & Armários para a guarda de pertences \\
\hline & $\begin{array}{l}\text { Distrações positivas ativas e passivas (TV, música, internet, aquário, jogos e } \\
\text { brincadeiras) }\end{array}$ \\
\hline & Poltronas confortáveis reclináveis para pacientes nas esperas \\
\hline \multirow{2}{*}{$\begin{array}{c}\text { Paisagismo e áreas } \\
\text { externas }\end{array}$} & Playground \\
\hline & Vista arborizada \\
\hline \multirow[t]{2}{*}{ Iluminação } & Ampla infusão de luz natural \\
\hline & Valorização da vista para o exterior \\
\hline \multirow{2}{*}{$\begin{array}{l}\text { Integração } \\
\text { tecnológica }\end{array}$} & Circuito interno de televisão \\
\hline & Controle sistêmico digital de segurança e de fluxos \\
\hline
\end{tabular}

Os diversos instrumentos de APO se mostraram adequados para a pesquisa qualitativa, podendo incorporar medições e levantamento de percepções ambientais, quando há disponibilidade maior de tempo e recursos de pesquisa, e permissão da instituição. A partir da aplicação de diferentes instrumentos de APO - a análise de benchmarks internacionais, as entrevistas com especialistas e a avaliação do estudo de caso central, CIB -, o trabalho elencou os principais recursos de humanização na arquitetura que podem contribuir para o bemestar dos usuários em ambiente de quimioterapia ambulatorial. Além disso, a pesquisa apontou que os resultados podem ser aplicados para os demais setores assistenciais do edifício da saúde, considerando suas especificidades.

Ao implementar ações de humanização da arquitetura, o trabalho do voluntariado tem sido significativo nos ambientes da saúde, mas ainda não se identificam seus reais desdobramentos no projeto arquitetônico hospitalar no Brasil. A transformação ambiental em locais alegres e acolhedores no edifício da saúde, assegurando a privacidade e a socialização, é estratégica relevante ao bom atendimento aos pacientes, submetidos aos desgastes do tratamento árduo e prolongado, e influi positivamente no bem-estar dos familiares e dos profissionais de saúde.

As conclusões estimulam a produção de novas pesquisas no sentido de identificar alternativas arquitetônicas que favoreçam o melhor atendimento ao público infanto-juvenil e aos demais usuários envolvidos. Os resultados da aplicação da APO no estudo de caso permitiram identificar a tendência de um impacto significativo no bem-estar das crianças que o ambiente propício produz. No entanto, seria necessário ampliar o estudo para escalas relevantes, como uma sistematização da pesquisa em território nacional por meio de amostra significativa com aplicação de questionário on-line de múltipla escolha ou outros aplicativos, cujos resultados poderiam contribuir sobremaneira na melhoria da qualidade desse tipo de ambiente.

Sobre os rumos da arquitetura para o ambiente de quimioterapia, a pesquisa mostrou ser irrefutável a importância do conhecimento sobre o cenário atual. Interagindo com equipe multidisciplinar e de posse do conhecimento sobre as tendências tecnológicas e a humanização na arquitetura, caberá ao arquiteto identificar os desdobramentos desses avanços não só sobre o edifício, mas também sobre sua organização interna,e realizar proposições projetuais antevendo situações de futuro crescimento e objetivando, em última 
instância, a elaboração de novos projetos e adaptações de ambientes construídos mais próximos das necessidades, da satisfação e do bem-estar dos usuários.

\section{Referências}

AGÊNCIA NACIONAL DE VIGILÂNCIA SANITÁRIA. Resolução RDC 50, de 21 de fevereiro de2002. Dispõe sobre o regulamento técnico para planejamento, programação, elaboração e avaliação de projetos físicos de Estabelecimentos Assistenciais de saúde. Diário [da] República Federativa do Brasil, Brasília, DF,21 fev.2002. Disponível em:

http://bvsms.saude.gov.br/bvs/saudelegis/anvisa/2002/rdc0050_21_02_2002.html. Acesso em: 11 fev. 2019.

ANN \& ROBERT H. LURIE CHILDREN'S HOSPITAL OF CHICAGO. [Imagem]. ArchDaily. Disponível em: https://www.archdaily.com/909319/. Acesso em 6 abr. 2019.

BRASIL. Lei no 11.104, de 21 de março de 2005. Dispõe sobre a obrigatoriedade de instalação de brinquedotecas nas unidades de saúde que ofereçam atendimento pediátrico em regime de internação. Diário Oficial [da] República Federativa do Brasil, Brasília, DF, 21 mar 2005. Disponível em: http://www.planalto.gov.br/ccivil_03/_Ato2004-2006/2005/Lei/L11104.htm. Acesso em: 13 mar.2019.

BRASIL. Lei no 13.297, de 16 de junho de 2016, que regulamenta o trabalho voluntário no Brasil. Diário Oficial [da] República Federativa do Brasil,17 jun. 2016. Disponível em: http://www.planalto.gov.br/ccivil_03/_ato2015-2018/2016/lei/113297.htm. Acesso em: 13 mar.2019.

BRASIL. Lei no 8.069, de 13 de julho de 1990. Dispõe sobre o Estatuto da Criança e do Adolescente e dá outras providências. Diário Oficial [da] República Federativa do Brasil, Brasília, DF, 14 jul.1990. Disponível em: http://www.planalto.gov.br/ccivil_03/Leis/L8069.htm. Acesso em: 11 mar. 2019.

BRASIL. Ministério da Saúde. Secretaria de Atenção à Saúde. Ambiência. 2. ed. Brasília, 2006.

BRASIL. Ministério da Saúde. Secretaria Executiva. Núcleo Técnico da Política Nacional de Humanização. HumanizaSUS: Política Nacional de Humanização. Brasília: Ministério da Saúde, 2004.

CENTRO DE CÂNCER DA UNIVERSIDADE DO ARIZONA. [Imagem]. 2017. Archdaily. Disponível em: https://www.archdaily.com.br/br/804662/centro-do-cancer-da-universidade-do-arizona-zgf-architects. Acesso em 8 maio 2019.

CENTRO INFANTIL BOLDRINI. História. Disponível em: http://www.boldrini.org.br/\#historia. Acesso em: 14 fev. 2020.

GRUPO DE APOIO AO ADOLESCENTE E À CRIANÇA COM CÂNCER. Humanização. São Paulo. Disponível em: https://graacc.org.br/. Acesso em: 16 abr. 2019.

HOSPITAL INFANTIL NEMOURS. [Imagem]. Archdaily. Disponível em: https://www.archdaily.com.br/br/01-163632/hospital-infantil-nemours-slash-stanley-beaman-andsears.Acesso em: 7 maio 2019.

INSTITUTO DESIDERATA. Humanização em Oncologia Pediátrica Uma experiência de ambientação de hospitais públicos no Rio de Janeiro. Rio de Janeiro: Instituto Desiderata, 2015. 68f. Disponível em: http://desiderata.org.br/. Acesso em: 8 abr. 2019.

JORDANA, Sebastian Suzhou Children's Hospital, HKS 31.2011. Archdaily. Disponível em: https://www.archdaily.com/108031/suzhou-childrens-hospital-hks. Acesso em: 6 abr. 2019.

LOTUS SIGN. Adesivagem de parede para Hospital Infantil Darcy Vargas. São Paulo. Disponível em: http://www.lotussign.com.br/portfolio/adesivagem-de-parede-decorativa-para-o-hospital-infantil-darcyvargas/. Acesso em: 12 abr. 2019.

LUKIANTOCHUKI, M. A.; SOUZA, G. B. Humanização da arquitetura hospitalar. Arquitextos, São Paulo, v. 10, n.118.01, mar. 2010.

MAGALHÃES, I. Adesivagem de parede decorativa para o Hospital Infantil Darcy Vargas. São Paulo, 2018. Disponível em: http://www.lotussign.com.br/portfolio/adesivagem-de-parede-decorativa-para-ohospital-infantil-darcy-vargas/. Acesso em: 12 abr. 2019.

MORENO, S. Five ways to humanize health care. Frame, Amsterdam, n.121, p.140-151, mar.2018. 
PEDRO, I. C. S. et al. Ambulatório HC Criança: espaço exclusivo para crianças e adolescentes como diferencial na qualidade da assistência. Revista Qualidade HC, Ribeirão Preto, v.124, p. 37-41, 2018.

PESSATTI, M. P. A intersecção Arquitetura e Saúde: quando o problema é a falta de espaço na unidade de saúde, qual é o espaço que falta? 2008. Dissertação (Mestrado em Engenharia Civil) - Programa de PósGraduação em Saúde Coletiva, Faculdade de Ciências Médicas, Universidade de Campinas, Campinas, 2008.

SANOFF, H. Creating environments for young children. Mansfield, Ohio: Book Masters, 1995.

THOMAZONI, A. D. L. A definição do partido arquitetônico pautado nos estudos dos fluxos frente à modernização de hospitais complexos. São Paulo, 2016.Tese (Doutorado em Arquitetura) - Faculdade de Arquitetura e Urbanismo, Universidade de São Paulo, São Paulo, 2016.

UNIVERSITY OF ARIZONA CANCER CENTER / ZGF Architects. [Imagem]. Archdaily. Disponível em: https://www.archdaily.com/797911/university-of-arizona-cancer-center-zgf-

architects?ad_source=search\&ad_medium=search_result_all. Acesso em: 11 abril 2019.

\section{Agradecimentos}

Especiais agradecimentos à Capes, pela concessão da bolsa, ao Centro Infantil Boldrini, pelo acolhimento da pesquisa, e aos entrevistados,por suas valiosas contribuições.

Andrea D'Angelo Leitner

Departamento de Arquitetura e Construção | Universidade Estadual de Campinas | Rua Saturnino de Brito, 224, Cidade Universitária Zeferino Vaz | Campinas - SP - Brasil | CEP 13083-889 | Tel.: (11) 99961-2484 | E-mail: andrealeitner@gmail.com

Silvia Mikami Pina

Departamento de Arquitetura e Construção | Universidade Estadual de Campinas | Tel.: (11) 98273-7675 | E-mail: smikami@unicamp.br

\section{Ambiente Construído}

Revista da Associação Nacional de Tecnologia do Ambiente Construído

Av. Osvaldo Aranha, 99 - $3^{\circ}$ andar, Centro

Porto Alegre - RS - Brasil

CEP 90035-190

Telefone: +55 (51) 3308-4084

Fax: +55 (51) 3308-4054

www.seer.ufrgs.br/ambienteconstruido

E-mail: ambienteconstruido@ufrgs.br 